\title{
Jugador en serie: los dibujos de Julio Hevia
}

\author{
El alcance de los dibujos de Julio Hevia recae en lo complejo, lo disperso, lo particular y lo
} virtual. Intentar descifrarlos a partir de un molde es un ejercicio forzado, mejor sería volcar un aparato hermenéutico in situ; esto es, ensayar posibles interpretaciones sobre la marcha.

\section{CHRISTOPHER ROJAS QUISPE}

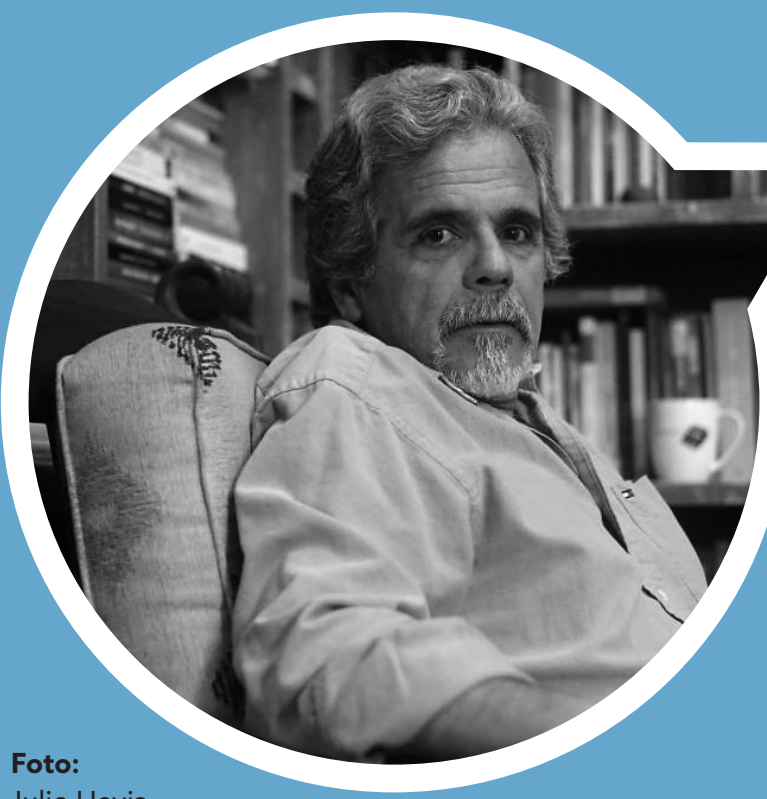

Movimiento de ida, vuelta y revuelta los que realizaba en sus trazos de tensión especulary modular. Sus collages, probablemente inspirados en Pollock, buscan y rebuscan lo accesorio en lo fundamental y lo vital en lo que parece no tener importancia. De esa forma, realzaba aquello que normalmente dejamos de lado, sea porque no lo vemos o porque le restamos relevancia. No obstante lo anterior, los espacios libres que el yuxtaponer deja son las sustracciones necesarias, completadas obviamente por las adiciones requeridas del ojo que las recorre.

Referirnos a Hevia artista, faceta aún desconocida para muchos, es hablar del que crea y troca mecanismos de escucha y amplifica aquello que oye sobre la cancha. Es decir, jugar sobre el "durante", dibujando, cortando y pegando; trazando elipsis imaginarias e imposibles; superponiendo texturas y formas. ¿Lo novedoso? El gramado es un rectángulo de cartulina.

Él siempre enfatizó la interdisciplinariedad inmanente al conocimiento, suerte de puerta giratoria a través de la cual accedemos de un campo a otro. De modo que un dibujo suyo es un ensayo, una propuesta, una perspectiva: un sistema estéticamente teórico o una teoría estéticamente fundamentada.

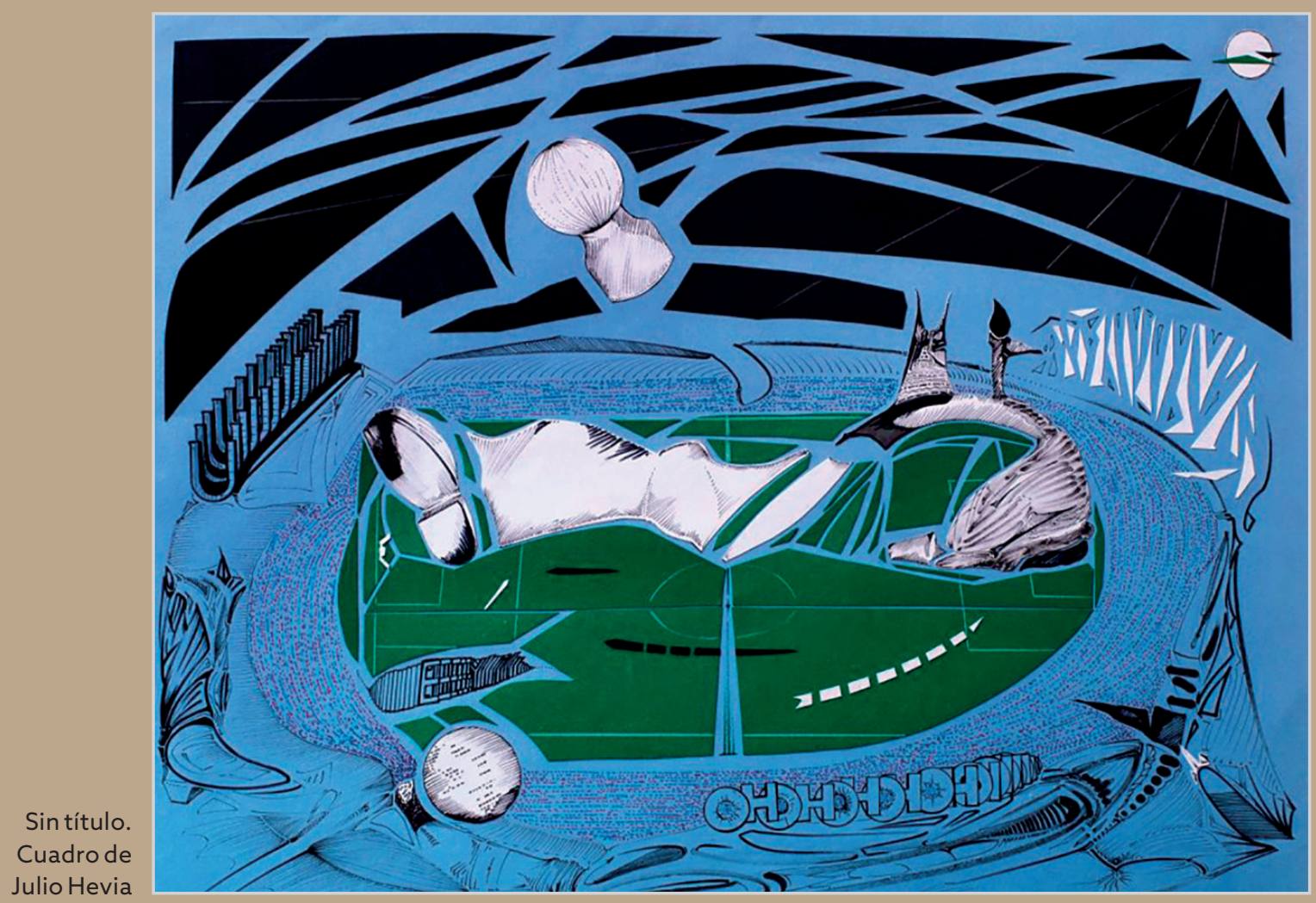


Mundo pausado y fragmentado el que expone, es una invitación a adentrarse en las pasiones y el universo que tanto lo sedujeron; congelar el campo visual y fraccionarlo; gatillar un sistema de ralentí a través del cual capturarlo para un disfrute mayor. A modo de ejercicio didáctico, recuérdese Life lessons de Historias de Nueva York (New York Stories, 1989) de Martin Scorsese y, más precisamente, el momento en que Lionel Dobie, interpretado por Nick Nolte, espera el arribo de su musa y cómo, de a pocos, la cámara deviene globo ocular, mira y coloca en la mira.

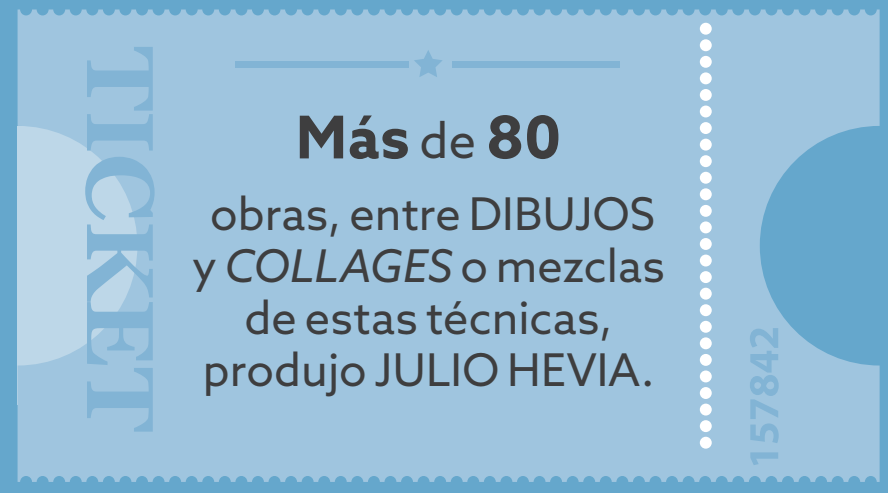

A medida que se amplía, se devela su objeto del deseo y el estado delartista: gestos extasiados, cabello desordenado, barba crecida y el trance en el que se encuentra, reflejado al arrojar el cigarrillo mecánicamente, tener las uñas mugrosas y las botas con restos de color azul y blanco. Finalmente, son las porciones los elementos que componen la vida del pintortodo es instante visual, lecciones de vida que él deberá aprender a aprehender y volcar sabiamente sobre el lienzo.

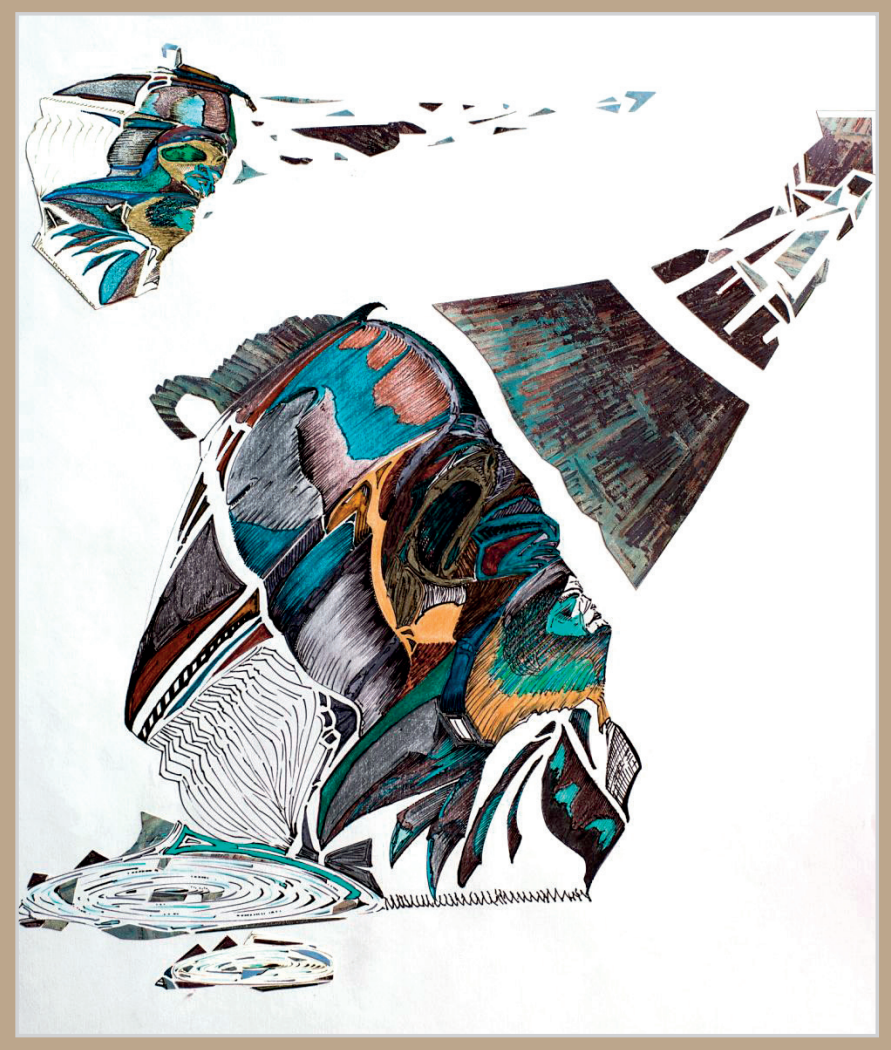

Huiro (cocha), de Julio Hevia
A propósito de ello, hay que recalcar, diríamos que en plano de detalle, el carácter lúdico que cruza la plástica del artista, sobre todo en la segunda y tercera etapa: lo liso se vuelve poroso, salta a la vista; una línea, una circunferencia y un cuadro se sublevan y una superposición se diluye para volverse ajuntar.

Habrá quienes digan que sus dibujos llegan nada más que a confirmar lo tardío y, en ese sentido, innecesario de su propuesta. Otros más osados podrían argüir que es un artista póstumo y, como tal, resultado exclusivamente de su labor intelectual y notoriedad mediática; es decir, como contrabandeando al escritor.

Lo cierto es que los caminos del artista bien pueden ser teóricos y los del teorizador arribar a lo artístico. Arte o artilugio, crear es recrear, pegar es despegar, mostrar es ocultar, hablar es callar y engullir es beber, habría respondido él.

Cabe resaltar que Julio poseía un filtro nietzschiano, de modo que el mundo, el sujeto y la vida son en tanto devenires constantes. Lo interpretable está imbricado en cada personaje. Su obra, ergo, es un libro abierto, un guion narrativo que nosotros, los paseantes, debemos interpretar a medida que circulamos, deambulamos, jugamos, nos embragamos y desembragamos. Ciertamente, al final, embebidos de tanto cuadre y descuadre, terminamos insertos en una circulación constante sin principio ni fin, como la pieza que brota y te eyecta a un lugar distante y distinto. Recurrencia de lo novedoso.

La efervescencia de las diversas temáticas volcadas sobre los pliegos de cartón refleja lo intrincado de su mirada, y es en esta que confirmamos su presencia entre nosotros — no olvidemos que la imagen es presente constante-y la vitalidad de la estela heredada de él, que recorre las calles de Lima. Porque Julio era transeúnte, transitaba de un arte a otro, del aula a la calle, del escribir al hablar, del comer al reflexionar, del enseñar al dibujar, del écran cinematográfico al trazo y al recorte. He ahí su mayor aporte: moverse siempre, explorando sin fin los vericuetos de la cotidianeidad con esa sapiencia tan suya, llevando a cabo híbridos al paso, esta vez marinando colores, formas y pulsos. Pues como el mismo diría y sus obras lo cantan: todo es mestizaje, todo es pasión y todo es arte. 